\title{
Synthetic genistein derivatives as modulators of glycosaminoglycan storage
}

\author{
Anna Kloska' ${ }^{1}$ Magdalena Narajczyk², Joanna Jakóbkiewicz-Banecka' ${ }^{1}$ Grzegorz Grynkiewicz ${ }^{3}$, Wiesław Szeja ${ }^{4}$, \\ Magdalena Gabig-Cimińska, ${ }^{1,5}$ and Grzegorz Węgrzyn ${ }^{1 *}$
}

\begin{abstract}
Background: Mucopolysaccharidoses (MPS) are severe metabolic disorders caused by accumulation of undegraded glycosaminoglycans (GAGs) in lysosomes due to defects in certain lysosomal hydrolases. Substrate reduction therapy (SRT) has been proposed as one of potential treatment procedures of MPS. Importantly, small molecules used in such a therapy might potentially cross the blood-brain barrier (BBB) and improve neurological status of patients, as reported for a natural isoflavone, 5, 7-dihydroxy-3- (4-hydroxyphenyl)-4 H-1-benzopyran-4-one, also known as genistein. Although genistein is able to cross BBB to some extent, its delivery to the central nervous system is still relatively poor (below 10\% efficiency). Thus, we aimed to develop a set of synthetically modified genistein molecules and characterize physicochemical as well as biological properties of these compounds.

Methods: Following parameters were determined for the tested synthetic derivatives of genistein: cytotoxicity, effects on cell proliferation, kinetics of GAG synthesis, effects on epidermal growth factor (EGF) receptor's tyrosine kinase activity, effects on lysosomal storage, potential ability to cross BBB.

Results: We observed that some synthetic derivatives inhibited GAG synthesis similarly to, or more efficiently than, genistein and were able to reduce lysosomal storage in MPS III fibroblasts. The tested compounds were generally of low cytotoxicity and had minor effects on cell proliferation. Moreover, synthetic derivatives of genistein revealed higher lipophilicity (assessed in silico) than the natural isoflavone.
\end{abstract}

Conclusion: Some compounds tested in this study might be promising candidates for further studies on therapeutic agents in MPS types with neurological symptoms.

Keywords: Mucopolysaccharidoses, Substrate reduction therapy, Synthetic derivatives of genistein

\section{Background}

Mucopolysaccharidoses (MPS) are rare lysosomal storage disorders caused by deficiencies in activities of several different lysosomal hydrolases. Mutations in genes coding for these enzymes lead to defects in degradation of glycosaminoglycans (GAGs) [1,2]. Excessive accumulation of undegraded GAGs in lysosomes causes severe problems in most tissues and organs and usually leads to death in childhood [2]. Currently, only two therapeutic procedures are available for treatment of some of MPS types: bone marrow (or hematopoietic cell) transplantation and enzyme replacement therapy

\footnotetext{
* Correspondence: wegrzyn@biotech.univ.gda.pl

'Department of Molecular Biology, University of Gdańsk, Kładki 24, Gdańsk 80-822, Poland

Full list of author information is available at the end of the article
}

(ERT) [3]. The former procedure is the therapy of choice in MPS I, as it can halt neurocognitive decline when performed early, preferably before the age of 2.5 years [4]. However, efficacy has only been demonstrated in MPS I and MPS VI, and not in MPS III [3,4]. The latter treatment is based on administration of the lacking enzyme, and it is currently available for MPS I, MPS II and MPS VI [5]. Although this treatment is to some extent effective in management of somatic symptoms of the disease, in many MPS types (MPS IH, MPS II, all MPS III subtypes, MPS VII) central nervous system (CNS) is also affected, and ERT seems to be of low efficacy in treatment of neurological symptoms because of the poor delivery of enzyme molecules to CNS across the blood-brain barrier (BBB) $[4,6]$.

\section{Biomed Central}


Substrate reduction therapy (SRT) is one of putative alternative methods for MPS treatment [6]. A specific kind of SRT for MPS, based on administration of genistein (5, 7-dihydroxy-3- (4-hydroxyphenyl)-4 H1-benzopyran-4-one also known as 4', 5, 7trihydroxyisoflavone), has been proposed [7]. In vitro, genistein significantly inhibits GAG synthesis and results in a decrease in lysosomal storage in MPS cells [7]. Expression of genes coding for enzymes involved in GAG synthesis might be controlled by signalling pathways dependent on a tyrosine kinase activity of epidermal growth factor receptor (EGFR) $[8,9]$, and genistein has been reported to inhibit this enzymatic activity [10]. In fact, genistein-mediated SRT was reported to act due to inhibition of phosphorylation of EGFR [11] and subsequent putative modulation of gene expression. Therefore, this specific kind of SRT has been named 'gene expression-targeted isoflavone therapy' or GET IT [12-14].

Since genistein was reported to cross the BBB to some extent [15], it has been suggested that GET IT might be effective in treatment of neurological symptoms of MPS. In fact, in vivo studies performed with MPS IIIB mouse model revealed a significant reduction of lysosomal storage in liver of MPS IIIB mice treated with genistein for 8 weeks [16], and correction of the abnormal behavior in a long-term (9 month) experiment with high genistein dose (160 mg/kg/day) [17]. Additionally, in both open label and placebo-controlled studies with MPS III patients treated with a genistein-rich soy extract at relatively low doses (5-15 $\mathrm{mg} / \mathrm{kg} /$ day), some - though only limited - positive effects on urinary and plasma GAG levels, hair morphology, cognitive functions and behavior were reported [18-22]. This low efficacy of GET IT in clinical trials, which is in contrast to promising results of experiments performed in vitro and with mice, has recently been suggested to be due to low genistein doses in former studies (5-15 mg/kg/day in clinical studies vs. $160 \mathrm{mg} / \mathrm{kg} /$ day in animal-based experiments) [14]. Nevertheless, other mechanisms, like limited effects of genistein in human body and/or low efficiency of crossing $\mathrm{BBB}$ by this isoflavone (this efficiency was estimated to be below $10 \%$ in rats [15]), could not be excluded.

Simultaneously to clinical trials, further laboratory experiments on GET IT have been performed and it was demonstrated that some other natural isoflavones, or even flavonoids, may also cause an inhibition of GAG synthesis and reduction of their accumulation in MPS cells [23,24]. Therefore, one might speculate that chemical modification(s) of genistein might improve either its efficiency in GAG synthesis inhibition or efficiency in crossing BBB. If so, GET IT could be of higher efficacy in MPS patients. In this study, we aimed to test a series of synthetic derivatives of genistein in terms of efficiency of GAG synthesis inhibition and potential ability to cross BBB.

\section{Methods}

\section{Chemicals}

Genistein was obtained at the Pharmaceutical Research Institute (Warsaw, Poland) on the pilot plant scale, according to proprietory method [25]. A method for regioselective derivatization of its phenolic groups was designed, based on unique, stable tetrabutylammonium salt [26]. Preparations of its synthetic derivatives were already described in connection with study of antiproliferative activity [27]. The derivatives listed in Table 1 have also been claimed as modulators of GAG storage in CNS (United States Patent no. US 8,178,609 B2; date of patent: May 15, 2012; inventors: Grynkiewicz G., Wegrzyn G., Szechner B., Tylki-Szymanska A., Wegrzyn A., Jakobkiewicz-Banecka J., Baranska S., Czartoryska B., Piotrowska E., title: Isoflavones for treating mucopolysaccharidoses). Stock solutions were prepared in dimethylformamide (DMF). MTT reagent (3-(4,5dimethylthiazol-2-yl)-2,5- diphenyltetrazolium bromide), purchased from Sigma (Germany), was dissolved in RPMI-1640 medium without phenol red (Sigma, Germany). Phosphate Bufered Saline (PBS), dimethylsulfoxide (DMSO) and dimethylformamide (DMF) were from Sigma (Germany).

\section{Cell lines and culture conditions}

Fibroblast cell lines obtained from MPS IIIA and MPS IIIB patients were used in all experiments. Human Dermal Fibroblast adult line (HDFa; Cascade Biologics, Portland, OR, USA) was used as a healthy control line. Cells were grown in Dulbecco's Modified Eagle Medium (DMEM) supplemented with $10 \%$ Fetal Bovine Serum (FBS) and $1 \mathrm{x}$ Antibiotic and Antimycotic Solution (all purchased from Sigma, Germany) at $37{ }^{\circ} \mathrm{C}$ in humidified $5 \% \mathrm{CO}_{2}$ atmosphere. GAG synthesis experiments were performed using Minimal Essential Medium without inorganic sulfates (MEM, Joklik's modified; Sigma, Germany).

\section{Cytotoxicity and proliferation assay}

Cytotoxicity and cell proliferation was assessed using MTT assay. Cells were seed in 96-well plates in a number of $6 \times 10^{3}$ cells per well (cytotoxicity assay) or $10^{3}$ cells per well (proliferation assay). After an overnight incubation, growth medium was substituted with medium supplemented with appropriate concentrations of genistein synthetic derivatives or $0.05 \%$ DMF as a control and cells were incubated for 24- or 48-hours (cytotoxicity assay) or for 7-days (proliferation assay). Then, medium was substituted with MTT solution $(1 \mathrm{mg} / \mathrm{ml}$ in RPMI1640 medium) and following 2-hour incubation at $37^{\circ} \mathrm{C}$ the amount of a purple formazan product dissolved in DMSO was quantified by measuring the absorbance at $550 \mathrm{~nm} . \mathrm{LC}_{50}$ (cytotoxicity assay) or $\mathrm{IC}_{50}$ (proliferation 
Table 1 Synthetic derivatives of genistein

\begin{tabular}{|c|c|c|c|}
\hline Symbol & IUPAC systematic name & $\begin{array}{l}\text { Molecular } \\
\text { formula }\end{array}$ & $\begin{array}{l}\text { Molecular } \\
\text { weight }\end{array}$ \\
\hline IFG-001 & 4-(5,7-dihydroxy-4-oxo-4 H-chromen-3-yl)phenyl 2-aminobenzoate & $\mathrm{C}_{22} \mathrm{H}_{15} \mathrm{NO}_{6}$ & 389.367 \\
\hline IFG-018 & 5-hydroxy-3-(4-hydroxyphenyl)-4-oxo-4 H-chromen-7-yl heptadecanoate & $\mathrm{C}_{31} \mathrm{H}_{40} \mathrm{O}_{6}$ & 508.65 \\
\hline IFG-021 & $\begin{array}{l}\text { 7-O-[(2,3,4,6-tetra-O-acetyl- } \beta \text {-D-galactopyranosyl)-1,4-(6-O-acetyl-hex-2-ene-a-D- erythropyranosyl)]-5-hydroxy-3- } \\
\text { (4-hydroxyphenyl)-4-H-chromen-4-one }\end{array}$ & $\mathrm{C}_{37} \mathrm{H}_{38} \mathrm{O}_{18}$ & 770.689 \\
\hline IFG-027 & 5-hydroxy-3-(4-hydroxyphenyl)-7-(prop-2-en-1- yloxy)-4 H-chromen-4-one & $\mathrm{C}_{18} \mathrm{H}_{14} \mathrm{O}_{5}$ & 310.30 \\
\hline IFG-032 & 4-[5,7-bis(acetyloxy)-4-oxo-4 H-chromen-3-yl]phenyl acetate & $\mathrm{C}_{21} \mathrm{H}_{16} \mathrm{O}_{8}$ & 396.35 \\
\hline IFG-034 & 5-hydroxy-3-(4-hydroxyphenyl)-4-oxo-4 H-chromen-7-yl)-2-acetyloxybenzoate & $\mathrm{C}_{24} \mathrm{H}_{16} \mathrm{O}_{8}$ & 432.39 \\
\hline IFG-035 & 5,7-bis(prop-2-en-1-yloxy)-3-[4-(prop-2-en-1- yloxy)phenyl]-4 H-chromen-4-one & $\mathrm{C}_{22} \mathrm{H}_{22} \mathrm{O}_{5}$ & 390.43 \\
\hline IFG-036 & ethyl 2-((5-hydroxy-3-(4-hydroxyphenyl)-4-oxo-4 H-chromen-7-yl)oxy)acetate & $\mathrm{C}_{19} \mathrm{H}_{16} \mathrm{O}_{7}$ & 356.33 \\
\hline IFG-037 & tert-butyl-2-((5-hydroxy-3-(4-hydroxyphenyl)-4-oxo-4 H-chromen-7-yl)oxy)acetate & $\mathrm{C}_{21} \mathrm{H}_{20} \mathrm{O}_{7}$ & 384.382 \\
\hline IFG-038 & tetrabutylamonium 5-\{[5-hydroxy-3-(4-hydroxyphenyl)-4-oxo-4 H-chromen-7-yl] oxy\}-5-oxopentanoate & $\mathrm{C}_{36} \mathrm{H}_{51} \mathrm{NO}_{8}$ & 625.1 \\
\hline IFG-042 & tert-butyl 2-[(3-\{4-[2-(tert-butoxy)-2- oxoethoxy]pheny|\}-5-hydroxy-4-oxo-4 H-chromen-7-yl)oxy]acetate & $\mathrm{C}_{27} \mathrm{H}_{30} \mathrm{O}_{9}$ & 498.52 \\
\hline IFG-043 & tert-butyl 2-[(3-\{4-[2-(tert-butoxy)-2-oxoethoxy]phenyl\}-5-hydroxy-4-oxo-4 H-chromen-7-yl)oxy]acetate & $\mathrm{C}_{22} \mathrm{H}_{16} \mathrm{O}_{5}$ & 360.36 \\
\hline IFG-046 & 2(2(2-((4-oxo-4 H-chromen-7-yl)oxy)ethoxy)ethoxy)ethyl)-4-methylbenzenesulfonate & $\mathrm{C}_{28} \mathrm{H}_{28} \mathrm{O}_{10} \mathrm{~S}$ & 556.14 \\
\hline IFG-048 & tert-butyl 2-[4-(5,7-dihydroxy-4-oxo-4 H-chromen-3-yl)phenoxy]acetate & $\mathrm{C}_{21} \mathrm{H}_{20} \mathrm{O}_{7}$ & 384.382 \\
\hline IFG-050 & 5-hydroxy-3-(4-hydroxyphenyl)- 7-O-(epoxymethyl)- 4-H-chromen-4-one & $\mathrm{C}_{18} \mathrm{H}_{14} \mathrm{O}_{6}$ & 326.30 \\
\hline IFG-051 & 7-(benzyloxy)-5-hydroxy-3-[4-(prop-2-en-1-yloxy)phenyl]-4 H-chromen-4-one & $\mathrm{C}_{25} \mathrm{H}_{20} \mathrm{O}_{5}$ & 400.42 \\
\hline IFG-052 & 4-[5-hydroxy-4-oxo-7-(prop-2-en-1-yloxy)-4 H- chromen-3-yl]phenyl 2-(acetyloxy)benzoate & $\mathrm{C}_{27} \mathrm{H}_{20} \mathrm{O}_{8}$ & 472.44 \\
\hline IFG-053 & $\begin{array}{l}\text { 2-(3-\{4-[7-(benzyloxy)-5-hydroxy-4-oxo-4 H-chromen-3-yl] phenoxymethyl\}-5-(1-cyano-1-methylethyl)phenyl)-2- } \\
\text { methylpropanenitrile }\end{array}$ & $\mathrm{C}_{37} \mathrm{H}_{32} \mathrm{~N}_{2} \mathrm{O}_{5}$ & 584.66 \\
\hline IFG-054 & 2-\{[5-hydroxy-3-(4-hydroxyphenyl)-4-oxo-4 H-chromen-7-yl]oxy\}acetic acid & $\mathrm{C}_{17} \mathrm{H}_{12} \mathrm{O}_{7}$ & 328.27 \\
\hline IFG-060 & 5-\{4-[7-(benzyloxy)-5-hydroxy-4-oxo-4 H-chromen-3-yl]phenoxy\}-5-oxopentanoic acid & $\mathrm{C}_{27} \mathrm{H}_{22} \mathrm{O}_{8}$ & 474.47 \\
\hline IFG-061 & 4-[7-(benzyloxy)-5-hydroxy-4-oxo-4 H-chromen-3-yl]phenyl 1-sodium pentanedioate & $\mathrm{C}_{27} \mathrm{H}_{21} \mathrm{O}_{8} \mathrm{Na}$ & 480.45 \\
\hline IFG-062 & 5-hydroxy-3-(4-hydroxyphenyl)-7-[(4- methoxyphenyl)methoxy]-4 H-chromen-4-one & $\mathrm{C}_{23} \mathrm{H}_{18} \mathrm{O}_{6}$ & 390.39 \\
\hline IFG-063 & [5-hydroxy-3-(4-hydroxyphenyl)-4-oxo-4 H-chromen-7-yl] prop-2-en-1-yl carbonate & $\mathrm{C}_{19} \mathrm{H}_{14} \mathrm{O}_{7}$ & 354.31 \\
\hline IFG-064 & 7-(benzyloxy)-5-hydroxy-3-[4-(propan-2-yloxy)phenyl]-4 H-chromen-4-one & $\mathrm{C}_{25} \mathrm{H}_{22} \mathrm{O}_{5}$ & 402.44 \\
\hline IFG-065 & 7-(benzyloxy)-5-(propan-2-yloxy)-3-[4-(propan-2-yloxy)phenyl]-4 H-chromen-4-one & $\mathrm{C}_{28} \mathrm{H}_{28} \mathrm{O}_{5}$ & 444.52 \\
\hline IFG-066 & 5,7-dihydroxy-3-[4-(propan-2-yloxy)phenyl]-4 H- chromen-4-one & $\mathrm{C}_{18} \mathrm{H}_{16} \mathrm{O}_{5}$ & 312.32 \\
\hline IFG-067 & 4-[7-(benzyloxy)-5-hydroxy-4-oxo-4 H-chromen-3-yl]phenyl acetate & $\mathrm{C}_{24} \mathrm{H}_{18} \mathrm{O}_{6}$ & 402.4 \\
\hline IFG-070 & methyl 2-\{[5-hydroxy-3-(4-hydroxyphenyl)-4-oxo-4 H-chromen-7-y|l]oxy\}acetate & $\mathrm{C}_{18} \mathrm{H}_{14} \mathrm{O}_{7}$ & 342.16 \\
\hline IFG-071 & 5-\{[5-hydroxy-3-(4-hydroxyphenyl)-4-oxo-4 H-chromen-7-yl]oxy\}pentyl acetate & $\mathrm{C}_{22} \mathrm{H}_{22} \mathrm{O}_{7}$ & 398.40 \\
\hline IFG-072 & 5-hydroxy-3-(4-hydroxyphenyl)-7-(3-hydroxypropoxy)-4 H-chromen-4-one & $\mathrm{C}_{18} \mathrm{H}_{16} \mathrm{O}_{6}$ & 328.31 \\
\hline IFG-073 & 5-hydroxy-7-(2-hydroxyethoxy)-3-(4-hydroxyphenyl)-4 H-chromen-4-one & $\mathrm{C}_{17} \mathrm{H}_{14} \mathrm{O}_{6}$ & 314.22 \\
\hline IFG-074 & tetrabutylamonium 2-\{[5-hydroxy-3-(4-hydroxyphenyl)-4-oxo-4 H-chromen-7-yl]oxy\}acetate & $\mathrm{C}_{33} \mathrm{H}_{47} \mathrm{O}_{7} \mathrm{~N}$ & 569.73 \\
\hline
\end{tabular}

assay) index values were determined relative to nontreated cultures (incubated with DMF only).

\section{Measurement of kinetics of GAG synthesis}

Cells seed in a number of $2 \times 10^{4}$ cells per well (48-well plate) were incubated in growth medium overnight. Then, the medium was substituted with another one, containing appropriate concentrations of genistein synthetic derivatives or $0.05 \%$ DMF as a control, and cells were grown for 48 hours. In the next step, the medium was substituted with growth medium without inorganic sulfates (MEM, Joklik's modified) mixed with standard DMEM medium (1:1) supplemented with FBS. GAGs were labeled with $20 \mu \mathrm{Ci} / \mathrm{ml}$ of $\mathrm{H}_{2}\left[{ }^{35} \mathrm{~S}^{\mathrm{O}} \mathrm{O}_{4}\right.$ (Hartmann Analytic) for 24 hours. Cells washed with PBS were digested for 3 hours with $0.03 \%$ papain (prepared in $100 \mathrm{mM}$ sodium acetate with $5 \mathrm{mM}$ L-cysteine, $\mathrm{pH}$ 7.0) (Merck KGaA, Darmstadt, Germany). ${ }^{35} \mathrm{~S}$ incorporation was measured in a scintillation counter and calculated per DNA amount, which was determined in samples with Quant-iT ${ }^{\mathrm{TM}}$ PicoGreen ${ }^{\circledR}$ dsDNA Reagent (Molecular Probes, Inc.) according to the manufacturer's protocol. 
Measurement of tyrosine kinase activity of EGF receptor Cells were seed in a number of $10^{4}$ cells per well of 96well plate. Following an overnight incubation, standard growth medium was substituted with the medium supplemented with appropriate concentrations of genistein synthetic derivatives or a potent tyrosine kinase inhibitor PD168390 (Merck KGaA, Darmstadt, Germany), and cells were incubated for 2 hours. Then, Epidermal Growth Factor (BD Biosciences, Franklin Lakes, NJ USA) was added to $100 \mathrm{ng} / \mathrm{ml}$ to induce EGF receptor autophosphorylation. After $15 \mathrm{~min}$ the medium was removed, and cells were fixed with $4 \%$ formaldehyde. Tyrosine kinase activity of EGF receptor was assessed using commercially available Cell-Based ELISA, Human Phospho-EGFR (Y1068) Immunoassay (R\&D Systems, Inc) according to the manufacturer's protocol.

\section{Electron microscopic studies}

Cells were incubated in growth medium supplemented with appropriate concentrations of tested compounds for 6 days. Following PBS washing, cells were fixed with $2.5 \%$ glutaraldehyde, and then with $1 \%$ osmium tetroxide and $1 \%$ potassium hexacyanoferrate (III) followed by ethanol dehydration. Sections of Epon 812 resin (Fluka, Germany) embedded cells were stained in lead citrate and uranyl acetate and examined under transmission electron microscope (Philips CM100). The number of different lysosomal structures was determined.

\section{Computational prediction of BBB penetration}

Following physicochemical parameters were determined for each synthetic derivative of genistein: molecular weight $(\mathrm{MW})$, octanol/water partition coefficient (cLogP), topological polar surface area (tPSA), the number of hydrogen bond donors (HBD) and hydrogen bond acceptors (HBA). Calculation of cLogP was performed on the basis of the chemical structure of compounds using ALOGPS 2.1 Program (VCCLAB) accessible via Internet (http:// www.vcclab.org) and assessment of tPSA was performed with MarvinSketch 5.2.6 (ChemAxon Ltd.) accessible via Internet (http://intro.bio.umb.edu/111-112/OLLM/111F98/ newclogp.html). Predicted $\operatorname{logBB}$ was assessed as proposed previously [28].

\section{Statistical analysis}

Effects of different concentrations of genistein synthetic derivatives on the number of lysosomal structures was tested by one-way ANOVA with Tukey's multiple comparisions as a post-hoc test. Statistical tests were performed using Statistica 8.0 [StatSoft, Poland] software with significance at $p<0.05$.

\section{Results}

Cytotoxicity and antiproliferative activity of genistein synthetic derivatives

We have tested 32 synthetic derivatives of genistein in order to establish cytotoxicity and antiproliferative activity in cultured fibroblasts after $24 \mathrm{~h}$ exposition to these compounds in a concentration range $1-30 \mu \mathrm{M}$. We found toxicity of several synthetic derivatives as low as that of genistein (compounds: IFG-032, IFG-034, IFG-036, IFG038, IFG-053, IFG-054, IFG-066, IFG-070, IFG-071, IFG072), while others exhibited higher cytotoxicity (see $\mathrm{LC}_{50}$ values, Table 2). Additionally, most of the compounds with low cytotoxicity (excluding IFG-053 and IFG-070) exhibited antiproliferative activity similar to or lower than that of genistein (see $\mathrm{IC}_{50}$ values, Table 2).

\section{Reduction of GAG synthesis by some genistein synthetic derivatives}

Since genistein inhibits GAG synthesis in a dosedependent manner, we have tested the effects of 32 genistein synthetic derivatives on GAG synthesis in fibroblast cultures. The level of GAG synthesis was estimated by measurement of $\left[{ }^{35} \mathrm{~S}\right] \mathrm{O}_{4}^{2-}$ uptake. Different genistein synthetic derivatives revealed various ability to inhibit GAG synthesis, though six of them (IFG032, IFG-038, IFG-042, IFG-043, IFG-061, IFG-071) decreased GAG synthesis after 3-day exposure to extent similar to that of genistein, while two (IFG-060, IFG-066) were even more effective (Table 2). Interestingly, some compounds (IFG-001, IFG-046, IFG-051, IFG-054, IFG-062, IFG-064) stimulated rather than inhibited GAG synthesis, with IFG-062 being a strong (over 4-fold) stimulator (Table 2).

\section{Decrease of lysosomal storage of GAGs by some genistein synthetic derivatives}

For further studies, we have selected the derivatives which revealed: (i) low cytotoxicity, (ii) antiproliferative activity similar to genistein, and (iii) efficient inhibition of GAG synthesis. Assuming that reduction in GAG synthesis may lead to a decrease in lysosomal storage, as concluded previously $[13,14]$, we assessed the storage in MPS cells by using electron microscopic techniques. The number of different lysosomal structures were counted and calculated per $100 \mu^{2}$ of cell crosssection. Examples of abnormal storage structures, observed in MPS IIIA and MPS IIIB cells, are presented in Figure 1.

We have observed a statistically significant decrease in the number of different abnormal lysosomal structures in MPS IIIA or MPS IIIB fibroblasts after 6-day exposure to all selected genistein synthetic derivatives at $30 \mu \mathrm{M}$, relative to untreated cells (Table 3). Average size of these structures did not change significantly 
Table 2 Cytotoxic and antiproliferative activities of genistein synthetic derivatives and their effects on kinetics of GAG synthesis in fibroblasts

\begin{tabular}{|c|c|c|c|}
\hline Compound & Cytotoxicity $\mathrm{LC}_{50}[\mu \mathrm{M}]$ & Proliferation $I C_{50}[\mu \mathrm{M}]$ & GAG synthesis [\%] \\
\hline IFG-001 & 13.9 & - & $120 \pm 56$ \\
\hline IFG-018 & 41.7 & - & $76 \pm 38$ \\
\hline IFG-021 & 11.0 & - & $75 \pm 25$ \\
\hline IFG-027 & 13.1 & - & $69 \pm 46$ \\
\hline IFG-032 & $n / c$ & 17.4 & $57 \pm 24$ \\
\hline IFG-034 & $n / c$ & 22.9 & $65 \pm 19$ \\
\hline IFG-035 & 22.6 & - & $93 \pm 70$ \\
\hline IFG-036 & $n / c$ & 11.2 & $64 \pm 21$ \\
\hline IFG-037 & 23.5 & - & $88 \pm 84$ \\
\hline IFG-038 & $n / c$ & 19.9 & $55 \pm 13$ \\
\hline IFG-042 & 22.0 & - & $48 \pm 29$ \\
\hline IFG-043 & 14.5 & - & $46 \pm 41$ \\
\hline IFG-046 & 20.7 & - & $118 \pm 72$ \\
\hline IFG-048 & 20.3 & - & $73 \pm 5$ \\
\hline IFG-050 & 11.6 & - & $100 \pm 65$ \\
\hline IFG-051 & 14.6 & - & $127 \pm 109$ \\
\hline IFG-052 & 15.8 & - & $74 \pm 19$ \\
\hline IFG-053 & $n / c$ & 53.0 & $92 \pm 52$ \\
\hline IFG-054 & $n / c$ & $\mathrm{n} / \mathrm{a}$ & $119 \pm 64$ \\
\hline IFG-060 & 14.9 & - & $31 \pm 8$ \\
\hline IFG-061 & 18.8 & - & $50 \pm 25$ \\
\hline IFG-062 & 12.1 & - & $403 \pm 206$ \\
\hline IFG-063 & 51.5 & - & $76 \pm 6$ \\
\hline IFG-064 & 6.6 & - & $133 \pm 77$ \\
\hline IFG-065 & 22.7 & - & $96 \pm 22$ \\
\hline IFG-066 & $n / c$ & 14.6 & $34 \pm 10$ \\
\hline IFG-067 & 15.1 & - & $96 \pm 38$ \\
\hline IFG-070 & $n / c$ & 48.1 & $101 \pm 30$ \\
\hline IFG-071 & $n / c$ & 17.9 & $49 \pm 20$ \\
\hline IFG-072 & $n / c$ & 14.1 & $79 \pm 42$ \\
\hline IFG-073 & 27.5 & - & $83 \pm 32$ \\
\hline IFG-074 & 44.1 & - & $88 \pm 39$ \\
\hline Genistein & $n / c$ & 16.9 & $55 \pm 31$ \\
\hline
\end{tabular}

Cytotoxicity is expressed as $\mathrm{LC}_{50}$ index value, i.e. concentration of the tested drug $[\mu \mathrm{M}]$ that is lethal to $50 \%$ of cells in a culture exposed to the tested compound for 24 hours. Antiproliferative activity is expressed as $I_{50}$ index value, i.e. concentration of the tested drug [ $\mu \mathrm{M}$ ] that causes $50 \%$ inhibition of cell proliferation in a culture exposed to the tested compound for 7 days. Kinetics of GAG synthesis is expressed as relative ${ }^{35} \mathrm{~S}$ incorporation into GAGs after 3-day exposure to derivatives of genistein at $30 \mu \mathrm{M}$ concentration. Labeling was conducted for 24 hours with $20 \mu \mathrm{Ci} / \mathrm{ml} \mathrm{H}_{2}\left[{ }^{35} \mathrm{~S}_{\mathrm{O}} \mathrm{O}_{4}\right.$. Radioactivity of incorporated ${ }^{35} \mathrm{~S}$ was measured in a scintillation counter, calculated per DNA amount [dpm/ng DNA] and expressed as the percentage of control, where $100 \%$ corresponds to the relative ${ }^{35} \mathrm{~S}$ incorporation into control (cell culture treated with $0.05 \%$ dimethylformamide).

$\mathbf{n} / \mathbf{c}$ denotes experiments in which no cytotoxicity was observed (over $90 \%$ of cells survived at concentrations ranging from 1 to $30 \mu \mathrm{M}$ ).

$\mathbf{n} / \mathbf{a}$ denotes experiments in which no antiproliferative activity was observed (relative proliferation was over $95 \%$ at concentrations ranging from 1 to $30 \mu \mathrm{M}$ ).

- denotes experiments in which $I C_{50}$ for antiproliferative activities could not be determined due to cytotoxic effects of the tested compounds.

(data not shown). Interestingly, unusual large vacuolelike structures of unknown function or content, were observed in cells treated with compound IFG-066 (Figure 1D).
Phosphorylation of EGF receptor in the presence of genistein synthetic derivatives

Reduction of GAG synthesis is assumed to be the result of impaired expression of genes coding for enzymes 

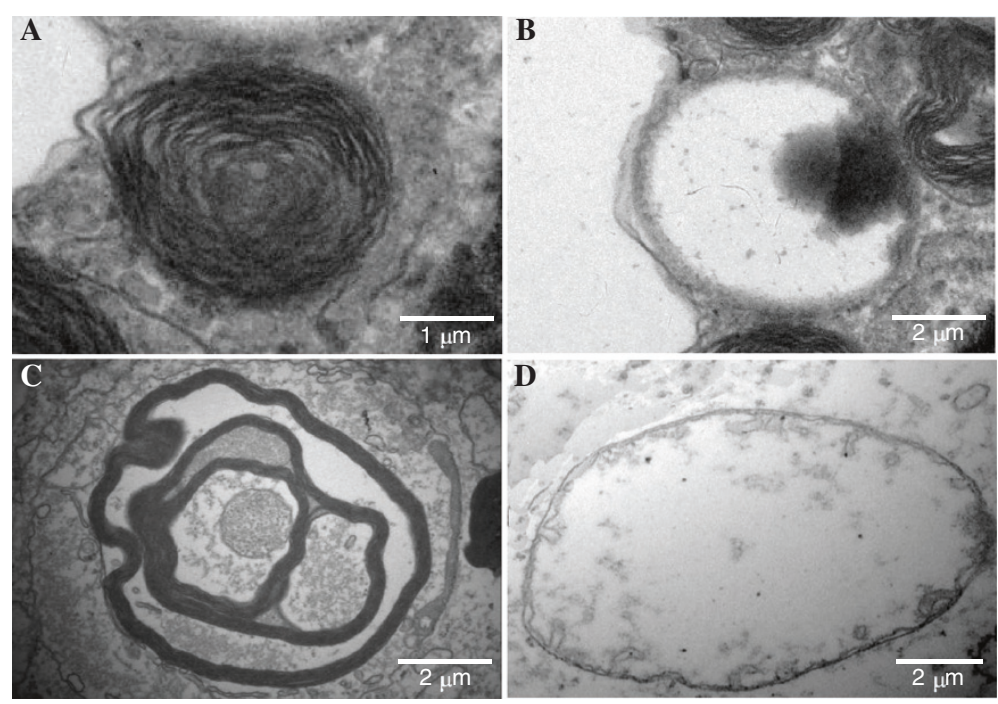

Figure 1 Electron microphotographs of different types of lysosomal structures in MPS III fibroblasts: lysosome with lamellar and electron-dense structure (A), lysosome of amorphous, flocculent and electron-lucent structure (B), complexed lysosomal structure (autophagolysosome) with storage material of different electron density (C), and vacuoles of unknown origin and function (D).

required for GAG production, and involves an intracellular signaling pathway depending of tyrosine kinase activity of EGFR [13,29]. Since genistein was reported to inhibit the activity of tyrosine kinase of EGFR, and thus to impair production of GAGs, we have tested the ability of some genistein synthetic derivatives (able to inhibit GAG synthesis) to impair phsophorylation of EGFR. We have observed that none of the tested synthetic derivatives

Table 3 Effect of synthetic derivatives of genistein at $30 \mu \mathrm{M}$ concentration on the number of different lysosomal structures in MPS IIIA and MPS IIIB fibroblasts

\begin{tabular}{|c|c|c|c|c|}
\hline \multirow[t]{2}{*}{ Compound } & \multicolumn{4}{|c|}{ Number of structures per $100 \mu \mathrm{m}^{2}$ of cellular cross section $\pm \mathrm{SD}$} \\
\hline & lamellar & complexed & amorphous & total number \\
\hline & \multicolumn{4}{|c|}{ MPS IIIA } \\
\hline None & $0.40 \pm 0.17$ & $0.35 \pm 0.35$ & $0.38 \pm 0.27$ & $1.13 \pm 0.50$ \\
\hline IFG-032 & $0.14 \pm 0.08 *$ & $0.22 \pm 0.11$ & $0.17 \pm 0.16 *$ & $0.53 \pm 0.19 *$ \\
\hline IFG-034 & $0.17 \pm 0.09 *$ & $0.27 \pm 0.14$ & $0.17 \pm 0.09 *$ & $0.61 \pm 0.20 *$ \\
\hline IFG-036 & $0.19 \pm 0.14 *$ & $0.28 \pm 0.16$ & $0.22 \pm 0.11$ & $0.73 \pm 0.31 *$ \\
\hline IFG-038 & $0.32 \pm 0.16$ & $0.27 \pm 0.13$ & $0.21 \pm 0.13$ & $0.80 \pm 0.24 *$ \\
\hline IFG-066 & $0.13 \pm 0.10 *$ & $0.16 \pm 0.08$ & $0.18 \pm 0.19 *$ & $0.48 \pm 0.17 *$ \\
\hline IFG-071 & $0.28 \pm 0.13$ & $0.26 \pm 0.09$ & $0.25 \pm 0.11$ & $0.79 \pm 0.22 *$ \\
\hline \multirow[t]{2}{*}{ IFG-072 } & $0.20 \pm 0.10 *$ & $0.28 \pm 0.10$ & $0.34 \pm 0.17$ & $0.82 \pm 0.23$ \\
\hline & \multicolumn{4}{|c|}{ MPS IIIB } \\
\hline None & $0.44 \pm 0.18$ & $0.14 \pm 0.10$ & $0.17 \pm 0.12$ & $0.75 \pm 0.31$ \\
\hline IFG-032 & $0.17 \pm 0.11 *$ & $0.10 \pm 0.07$ & $0.12 \pm 0.08$ & $0.40 \pm 0.20 *$ \\
\hline IFG-034 & $0.20 \pm 0.16 *$ & $0.06 \pm 0.05$ & $0.15 \pm 0.08$ & $0.41 \pm 0.16 *$ \\
\hline IFG-036 & $0.25 \pm 0.21 *$ & $0.12 \pm 0.11$ & $0.15 \pm 0.18$ & $0.50 \pm 0.34$ \\
\hline IFG-038 & $0.21 \pm 0.12 *$ & $0.10 \pm 0.10$ & $0.09 \pm 0.09$ & $0.41 \pm 0.18 *$ \\
\hline IFG-066 & $0.15 \pm 0.10 *$ & $0.11 \pm 0.14$ & $0.08 \pm 0.06$ & $0.34 \pm 0.23 *$ \\
\hline IFG-071 & $0.07 \pm 0.07 *$ & $0.07 \pm 0.06$ & $0.13 \pm 0.09$ & $0.26 \pm 0.13 *$ \\
\hline IFG-072 & $0.11 \pm 0.12 *$ & $0.16 \pm 0.08$ & $0.14 \pm 0.10$ & $0.41 \pm 0.20 *$ \\
\hline
\end{tabular}

Asterisks $(*)$ indicate statistically significant differences (one-way ANOVA with Tukey's multiple comparisions as a post-hoc test, $\mathrm{p}<0.05$ ) relative to control MPS IIIA and MPS IIIB cells (None) where no tested compound was added into culture medium. 
of genistein affects the tyrosine kinase activity of EGF R. Comparing to genistein or a potent tyrosine kinase inhibitor PD168390, no decrease of phosphorylation of EGFR was observed (Figure 2), suggesting that the synthesis of GAGs is reduced by investigated compounds by some other, unknown, mechanism(s).

\section{Computational prediction of BBB penetration}

Because genistein was reported to cross $\mathrm{BBB}$ only to some extent (several percent efficiency) we aimed to develop new derivatives of genistein with more lipophilic properties that could be able to cross this barrier more readily. Chemical modifications of the genistein molecule resulted, in most of the cases, in an increase of cLogP values, suggesting an increase in lipophilicity (Table 4). Moreover, some of genistein derivatives revealed tPSA values optimal for compounds able to cross BBB $\left(\right.$ tPSA $<90 \AA^{2}$ ) (Table 4). These results suggest a possible improvement in physicochemical properties of some modified genistein molecules compared to unmodified ones, in the light of efficiency of crossing BBB.

\section{Discussion}

An important issue in development of therapeutic approaches for MPS types with neurological symptoms is the ability of potential therapeutic agents to cross BBB. Enzyme replacement therapy, a treatment based on systematic, intravenous administration of the lacking enzyme, although effective - to some extent - in treatment of visceral organs, is of low efficacy in treatment of cases where the central nervous system is affected [1,6]. Alternative therapeutic approaches, such as substrate reduction therapies, are based on assumptions that lowmolecular-weight molecules might be able to cross BBB and penetrate the brain readily [29].

The results presented in this report indicate that some synthetic derivatives of genistein, particularly, IFG-060 and IFG-066, are potent inhibitors of GAG synthesis. Impairment of GAG synthesis by IFG-032, IFG-034, IFG-036, IFG-038, IFG-066, IFG-071 and IFG-072 was also an effective method for reduction of lysosomal storage in MPS IIIA and/or MPS IIIB cell cultures, as it was previously reported for genistein [7]. Studies on MPS IIIB mice suggested that GET IT may be a promising treatment $[16,17]$. Thus, according to results obtained in this study, we suggest that artificial genistein derivatives listed in Table 3 might be considered as potential drugs to be used in treatment of MPS.

In the development of new therapies, it is crucial for a potential drug to be safe for humans. In this study, some synthetic derivatives of genistein (including the efficient reducers of GAG storage, listed in Table 3) revealed low cytotoxicity and minor effects on cell proliferation. This appears important in the light of safety problems with another effective inhibitor of GAG synthesis, rhodamine B [30,31]. Therefore, it seems that some derivatives of genistein (e.g. IFG-032, IFG-034, IFG-036, IFG-038, IFG-066, IFG-071, IFG-072) possess desirable biological properties for a potentially safe and effective drug. Moreover, predicted changes of physicochemical properties of

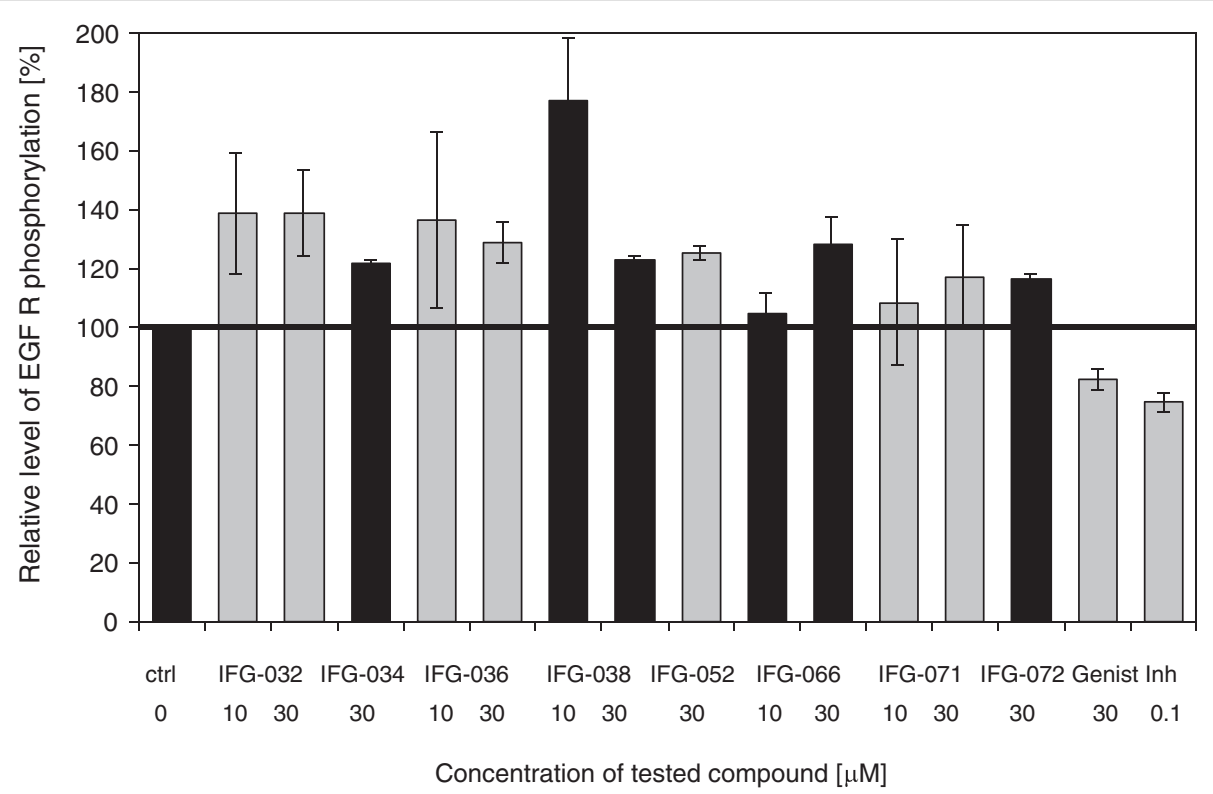

Figure 2 Effect of selected synthetic derivatives of genistein on the activity of tyrosine kinase of EGF R. Relative levels of EGF R phosphorylation relative to untreated control cells (ctrl), genistein (Genist) and artificial inhibitor - PD168390 (Inh), with bars indicating standard deviation between two independent experiments, is presented. Statistically significant $(p<0.05)$ decrease in relative level of EGFR phosphorylation, relative to the control cells (ctrl) was detected only for genistein (at $30 \mu \mathrm{M}$ ) and PD168390 (at $0.1 \mu \mathrm{M}$ ). 
Table 4 Physicochemical properties of synthetic derivatives of genistein assessed in silico

\begin{tabular}{|c|c|c|c|c|c|c|}
\hline Compound & $M W$ & cLogP & tPSA & HBA & HBD & $\log B B$ \\
\hline Genistein & 270.24 & 2.27 & 89.82 & 5 & 3 & -0.86 \\
\hline IFG-001 & 389.37 & 4.23 & 121.91 & 7 & 4 & -1.12 \\
\hline IFG-018 & 508.65 & 8.64 & 93.06 & 6 & 2 & 0.08 \\
\hline IFG-021 & 770.69 & 3.23 & 235.18 & 18 & 2 & -2.97 \\
\hline IFG-027 & 310.30 & 3.45 & 75.99 & 5 & 2 & -0.46 \\
\hline IFG-032 & 396.35 & 2.10 & 105.20 & 8 & 0 & -1.10 \\
\hline IFG-034 & 432.39 & 4.20 & 119.36 & 8 & 2 & -0.98 \\
\hline IFG-035 & 390.43 & 5.55 & 53.99 & 5 & 0 & 0.19 \\
\hline IFG-036 & 356.33 & 3.04 & 102.29 & 7 & 2 & -0.91 \\
\hline IFG-037 & 384.38 & 3.85 & 102.29 & 7 & 2 & -0.79 \\
\hline IFG-038 & 625.10 & 4.11 & 133.19 & 8 & 3 & -1.20 \\
\hline IFG-042 & 498.52 & 5.44 & 117.59 & 9 & 1 & -0.77 \\
\hline IFG-043 & 360.36 & 4.40 & 75.99 & 5 & 2 & -0.31 \\
\hline IFG-046 & 556.14 & 3.74 & 146.20 & 10 & 2 & -1.45 \\
\hline IFG-048 & 384.38 & 3.85 & 105.12 & 7 & 2 & -0.83 \\
\hline IFG-050 & 326.30 & 2.64 & 88.52 & 6 & 2 & -0.77 \\
\hline IFG-051 & 400.42 & 5.58 & 64.99 & 5 & 1 & 0.03 \\
\hline IFG-052 & 472.44 & 5.38 & 108.36 & 8 & 1 & -0.64 \\
\hline IFG-053 & 584.66 & 8.28 & 112.57 & 7 & 1 & -0.26 \\
\hline IFG-054 & 328.27 & 2.05 & 116.12 & 7 & 3 & -1.27 \\
\hline IFG-060 & 474.47 & 4.51 & 122.19 & 8 & 2 & -0.98 \\
\hline IFG-061 & 496.44 & 3.37 & 108.36 & 7 & 1 & -0.95 \\
\hline IFG-062 & 390.39 & 4.46 & 85.22 & 6 & 2 & -0.44 \\
\hline IFG-063 & 354.31 & 3.30 & 102.29 & 7 & 2 & -0.87 \\
\hline IFG-064 & 402.44 & 5.67 & 64.99 & 5 & 1 & 0.04 \\
\hline IFG-065 & 444.52 & 6.69 & 53.99 & 5 & 0 & 0.36 \\
\hline IFG-066 & 312.32 & 3.54 & 78.82 & 5 & 2 & -0.49 \\
\hline IFG-067 & 402.40 & 4.43 & 82.06 & 6 & 1 & -0.40 \\
\hline IFG-070 & 342.16 & 2.67 & 102.29 & 7 & 2 & -0.97 \\
\hline IFG-071 & 398.40 & 3.92 & 102.29 & 7 & 2 & -0.78 \\
\hline IFG-072 & 328.31 & 2.44 & 96.22 & 6 & 3 & -0.91 \\
\hline IFG-073 & 314.22 & 2.17 & 96.22 & 6 & 3 & -0.95 \\
\hline IFG-074 & 569.73 & 4.17 & 116.12 & 7 & 3 & -0.94 \\
\hline
\end{tabular}

MW - molecular weight [Da], cLogP - calculated octanol/water partition coefficient, tPSA - topological polar surface area $\left[\AA^{2}\right]$, HBA - hydrogen bond acceptor number $(\mathrm{O}+\mathrm{N})$, $\mathbf{H B D}$ - hydrogen bond donor number $(\mathrm{OH}+\mathrm{NH})$, LogBB - predicted BBB permeation.

some synthetic derivatives, relative to genistein (as assessed in silico), might result in improvement of ability to cross BBB (see Table 4). On the other hand, it is necessary to stress that such an improved crossing of BBB was only calculated in silico by using algorithms based on putative physicochemical properties of compounds, predicted from their formulas, according to previously described models [28]. One has to consider that such an approach, although based on solid physical and chemical assumptions, cannot reflect all biological processes, among which a possible active transport of tested compounds may be especially important. Therefore, it should be noted that for determination of actual abilities of penetration of $\mathrm{BBB}$ by all compounds described in this report, it will be necessary to perform experiments with either BBB models or (preferably) laboratory animals. Synthesis of labeled isoflavones should be the first step in the way to assess the real (not only calculated or predicted) efficiency of BBB penetration by tested genistein derivatives

Interestingly, the mechanism of action by which selected synthetic derivatives of genistein inhibit GAG production seems to be different from that described previously for genistein. Namely, contrary to this natural isoflavone, its artificial derivatives did not affect the EGF-dependent pathway, as they were not able to inhibit the EGFR kinase activity. It is worth noting that similar phenomenon was observed for various natural flavonoids causing GAG synthesis inhibition [24]. It is, therefore, tempting to speculate that various chemical modifications of the genistein molecule destroy its activity of the EGFR kinase inhibitor, while either retaining/enhancing or gaining a new function of GAG synthesis inhibitor by influencing another, as yet unidentified, biochemical pathway.

Finally, one should note that apart from genistein derivatives that decreased GAG synthesis, there were also compounds significantly enhancing the efficiency of this process, like IFG-062. Therefore, we assume that the set of artificial genistein derivatives described in this report might be a useful tool in further studies on molecular mechanisms of regulation of GAG synthesis.

\section{Conclusions}

Some synthetic derivaties of genistein revealed low cytotoxicity and small (if any) effects on cell proliferation, while slowing down GAG synthesis (though by a pathway other than inhibition of EGF receptor's tyrosine kinase activity) and decreasing lysosomal storage. These compounds had higher potential abilities to cross BBB than genistein. Thus, we suggest they are promising candidates for further studies on therapeutic agents in MPS types with neurological symptoms.

\section{Abbreviations \\ BBB: Blood-brain barrier; EGF: Epidermal growth factor; EGFR: Epidermal growth factor receptor; ERT: Enzyme replacement therapy; GAG (s): Glycosaminoglycan(s); GET IT: Gene expression-targeted isoflavone therapy; MPS: Mucopolysacccharidoses; SRT: Substrate reduction therapy.}

\section{Competing interest}

Genistein and its derivatives listed in Table 1 have been claimed as isoflavones for treating MPS in the United States Patent no. US 8,178,609 B2 (date of patent: May 15, 2012; inventors: Grynkiewicz G., Wegrzyn G. Szechner B., Tylki-Szymanska A., Wegrzyn A., Jakobkiewicz-Banecka J., 
Baranska S., Czartoryska B., Piotrowska E.; title: Isoflavones for treating mucopolysaccharidoses). The authors declare no other competing interest.

\section{Authors' contributions}

AK performed all experiments but electron microscopic studies, and performed both in silico and statistical analyses; MN designed electron microscopic experiments, executed them, analyzed their results and interpreted them; JJB designed other experiments, interpreted their results and participated in drafting the manuscript; GG and WS designed and performed syntheses of genistein derivatives; MGC analyzed the results and participated in drafting the manuscript; GW planned the study, coordinated the project, drafted the first version of the manuscript and prepared its final version. All authors read and approved the final manuscript.

\section{Acknowledgments}

This research was supported in part by National Science Center (Poland) (project grant no. N N301 668540), and was operated within the Foundation for Polish Science Team Programme co-financed by the EU European Regional Development Fund (grant no. TEAM/2008-2/7). A support from Polish MPS Society is greatly acknowledged.

\section{Author details}

${ }^{1}$ Department of Molecular Biology, University of Gdańsk, Kładki 24, Gdańsk 80-822, Poland. 'Laboratory of Electron Microscopy, University of Gdańsk, Kładki 24, Gdańsk 80-822, Poland. ${ }^{3}$ Pharmaceutical Research Institute, Rydygiera 8, Warsaw 01-793, Poland. ${ }^{4}$ Department of Chemistry, Silesian Technical University, Gliwice 44-100, Poland. ${ }^{5}$ Laboratory of Molecular Biology, (affiliated with University of Gdańsk), Institute of Biochemistry and Biophysics, Polish Academy of Sciences, Kładki 24, Gdańsk 80-822, Poland.

Received: 29 May 2012 Accepted: 16 July 2012

Published: 30 July 2012

\section{References}

1. Beck M: Mucopolysaccharidoses: clinical features and management. In Genetic Metabolic Disorders: Management, Costs and Sociomedical Aspects. Edited by vom Dahl S, Wendel U, Strohmeyer G. Cologne: Deutscher Arzte-Verlag; 2007:13-18.

2. Neufeld EF, Muenzer J: The mucopolysaccharidoses. In The metabolic and molecular bases of inherited disease. Edited by Scriver CR, Beaudet AL, Sly WS, Valle D. New York: McGraw-Hill Co; 2001:3421-3452.

3. Beck M: Therapy for lysosomal storage disorders. IUBMB Life 2010, 62:33-40.

4. de Ru MH, Boelens JJ, Das AM, Jones SA, van der Lee JH, Mahlaoui N, Mengel E, Offringa M, O'Meara A, Parini R, et al: Enzyme replacement therapy and/or hematopoietic stem cell transplantation at diagnosis in patients with mucopolysaccharidosis type I: results of a European consensus procedure. Orphanet J Rare Dis 2011, 6:55

5. Wraith JE: Enzyme replacement therapy for the management of the mucopolysaccharidoses. Int J Clin Pharmacol Ther 2009, 47(Suppl 1):63-65.

6. Beck M: New therapeutic options for lysosomal storage disorders: enzyme replacement, small molecules and gene therapy. Hum Genet 2007, 121:1-22.

7. Piotrowska E, Jakobkiewicz-Banecka J, Baranska S, Tylki-Szymanska A, Czartoryska B, Wegrzyn A, Wegrzyn G: Genistein-mediated inhibition of glycosaminoglycan synthesis as a basis for gene expression-targeted isoflavone therapy for mucopolysaccharidoses. Eur J Hum Genet 2006, 14:846-852.

8. Pisano MM, Greene RM: Epidermal growth factor potentiates the induction of ornithine decarboxylase activity by prostaglandins in embryonic palate mesenchymal cells: effects on cell proliferation and glycosaminoglycan synthesis. Dev Biol 1987, 122:419-431.

9. Tirone E, D'Alessandris C, Hascall VC, Siracusa G, Salustri A: Hyaluronan synthesis by mouse cumulus cells is regulated by interactions between follicle-stimulating hormone (or epidermal growth factor) and a soluble oocyte factor (or transforming growth factor beta1). J Biol Chem 1997, 272:4787-4794.

10. Akiyama T, Ishida J, Nakagawa S, Ogawara H, Watanabe S, Itoh N, Shibuya M, Fukami Y: Genistein, a specific inhibitor of tyrosine-specific protein kinases. J Biol Chem 1987, 262:5592-5595.
11. Jakobkiewicz-Banecka J, Piotrowska E, Narajczyk M, Baranska S, Wegrzyn G: Genistein-mediated inhibition of glycosaminoglycan synthesis, which corrects storage in cells of patients suffering from mucopolysaccharidoses, acts by influencing an epidermal growth factor-dependent pathway. J Biomed Sci 2009, 16:26

12. Wegrzyn G, Jakobkiewicz-Banecka J, Gabig-Ciminska M, Piotrowska E, Narajczyk M, Kloska A, Malinowska M, Dziedzic D, Golebiewska I, Moskot M, Wegrzyn A: Genistein: a natural isoflavone with a potential for treatment of genetic diseases. Biochem Soc Trans 2010, 38:695-701.

13. Jakobkiewicz-Banecka J, Piotrowska E, Gabig-Ciminska M, Borysiewicz E, Slominska-Wojewodzka M, Narajczyk M, Wegrzyn A, Wegrzyn G: Substrate reduction therapies for mucopolysaccharidoses. Curr Pharm Biotechnol 2011, 12:1860-1865.

14. Wegrzyn A: Gene expression-targeted isoflavone therapy. IUBMB Life 2012, 64:307-315

15. Tsai TH: Concurrent measurement of unbound genistein in the blood, brain and bile of anesthetized rats using microdialysis and its pharmacokinetic application. J Chromatogr A 2005, 1073:317-322.

16. Malinowska M, Wilkinson FL, Bennett W, Langford-Smith KJ, O'Leary HA, Jakobkiewicz-Banecka J, Wynn R, Wraith JE, Wegrzyn G, Bigger BW: Genistein reduces lysosomal storage in peripheral tissues of mucopolysaccharide IIIB mice. Mol Genet Metab 2009, 98:235-242.

17. Malinowska M, Wilkinson FL, Langford-Smith KJ, Langford-Smith A, Brown JR, Crawford BE, Vanier MT, Grynkiewicz G, Wynn RF, Wraith JE, et al: Genistein improves neuropathology and corrects behaviour in a mouse model of neurodegenerative metabolic disease. PLoS One 2010, 5:e14192.

18. Piotrowska E, Jakobkiewicz-Banecka J, Tylki-Szymanska A, Liberek A, Maryniak A, Malinowska M, Czartoryska B, Puk E, Kloska A, Liberek T, et al: Genistin-rich soy isoflavone extract in substrate reduction therapy for Sanfilippo syndrome: An open-label, pilot study in 10 pediatric patients. Curr Ther Res Clin Exp 2008, 63:166-179.

19. Piotrowska E, Jakobkiewicz-Banecka J, Maryniak A, Tylki-Szymanska A, Puk E, Liberek A, Wegrzyn A, Czartoryska B, Slominska-Wojewodzka M, Wegrzyn G Two-year follow-up of Sanfilippo Disease patients treated with a genistein-rich isoflavone extract: assessment of effects on cognitive functions and general status of patients. Med Sci Monit 2011, 17:CR196-CR202.

20. Delgadillo V, O'Callaghan Mdel M, Artuch R, Montero R, Pineda M: Genistein supplementation in patients affected by Sanfilippo disease. J Inherit Metab Dis 2011, 34:1039-1044.

21. Malinova V, Wegrzyn G, Narajczyk M: The use of elevated doses of genistein-rich soy extract in the gene expression-targeted isoflavone therapy (GET IT) for Sanfilippo disease patients. JIMD Rep 2012, 5:21-25.

22. de Ruijter J, Valstar MJ, Narajczyk M, Wegrzyn G, Kulik W, ljlst L, Wagemans T, van der Wal WM, Wijburg FA: Genistein in Sanfilippo disease: a randomized controlled crossover trial. Ann Neurol 2012, 71:110-120.

23. Arfi A, Richard M, Gandolphe C, Scherman D: Storage correction in cells of patients suffering from mucopolysaccharidoses types IIIA and VII after treatment with genistein and other isoflavones. J Inherit Metab Dis 2010, 33:61-67.

24. Kloska A, Jakobkiewicz-Banecka J, Narajczyk M, Banecka-Majkutewicz Z, Wegrzyn G: Effects of flavonoids on glycosaminoglycan synthesis: implications for substrate reduction therapy in Sanfilippo disease and other mucopolysaccharidoses. Metab Brain Dis 2011, 26:1-8.

25. Grynkiewicz G: Synthetic genistein as a prospective active ingredient for nutrition and medicine. Pol J Food Nutr Sci 2002, 52(Suppl 2):99-105.

26. Grynkiewicz G, Zegrocka-Stendel O, Pucko W, Ramza J, Kościelecka A, Kołodziejski W, Woźniak K: X-ray and ${ }^{13}$ C CP MAS investigations of structure of two genistein derivatives. J Mol Struct 2004, 694:121-129.

27. Rusin A, Krawczyk Z, Grynkiewicz G, Gogler A, Zawisza-Puchalka J, Szeja W: Synthetic derivatives of genistein, their properties and possible applications. Acta Biochim Pol 2010, 57:23-34.

28. Clark DE: Rapid calculation of polar molecular surface area and its application to the prediction of transport phenomena. 2. Prediction of blood-brain barrier penetration. J Pharm Sci 1999, 88:815-821.

29. Jakobkiewicz-Banecka J, Wegrzyn A, Wegrzyn G: Substrate deprivation therapy: a new hope for patients suffering from neuronopathic forms of inherited lysosomal storage diseases. J App/ Genet 2007, 48:383-388.

30. Roberts AL, Thomas BJ, Wilkinson AS, Fletcher JM, Byers S: Inhibition of glycosaminoglycan synthesis using rhodamine $B$ in a mouse model of mucopolysaccharidosis type IIIA. Pediatr Res 2006, 60:309-314. 
31. Roberts AL, Rees MH, Klebe S, Fletcher JM, Byers S: Improvement in behaviour after substrate deprivation therapy with rhodamine $B$ in a mouse model of MPS IIIA. Mol Genet Metab 2007, 92:115-121.

doi:10.1186/1479-5876-10-153

Cite this article as: Kloska et al: Synthetic genistein derivatives as modulators of glycosaminoglycan storage. Journal of Translational Medicine 2012 10:153.

\section{Submit your next manuscript to BioMed Central} and take full advantage of:

- Convenient online submission

- Thorough peer review

- No space constraints or color figure charges

- Immediate publication on acceptance

- Inclusion in PubMed, CAS, Scopus and Google Scholar

- Research which is freely available for redistribution 